\title{
Educação e sociedade democrática: interpretacões sociológicas e desafios à formação política do educador
}

ALEKANDRE SILUA VIRGINIO"

\section{Resumo}

Neste trabalho, procuramos situar o papel da educação na constituição de uma sociedade democrática. A relação entre democracia e educação funda-se na identificação dos predicados da primeira, sobretudo, a partir das contribuições de Karl Mannheim, e nas propriedades da segunda, mormente em sua dimensão política, estribo para a convergência entre processos curriculares e necessidades sociais. Tomando por base a realidade nacional, asseveramos que a construção de uma consciência e personalidade democrática decorre da consecução de uma outra sociabilidade, qual seja, consoante aos valores da reciprocidade e da cooperação, tanto quanto sensível à qualificação dos termos que definem, objetiva e subjetivamente, a qualidade de vida. Tal qualidade decorre, ademais, do desenvolvimento das interpretações críticas e/ou propostas criativas colocadas na e pela experiência cotidiana. Considerando a natureza precária de nossa cidadania, tanto quanto os desafios educacionais em curso, colocamos em relevo o desafio da formação política do educador. Esta dimensão formativa, principalmente se levarmos em conta as carências e dificuldades das classes populares, pode, se observadas e desenvolvidas as relações ético-políticas que permeiam o saber e o fazer docente, conferir um outro cariz, de natureza humanista, ao processo de socialização escolar. Mais do que isso, pode significar a mediação necessária, ainda que não suficiente, entre utopia democrática e sociedade democrática,

* Doutor em Sociologia da Universidade Federal do Rio Grande do Sul (Brasil). Professor do Departamento de Sociologia da Universidade Federal do Rio Grande do Sul. Colaborador externo do Grupo de Investigação de Pedagogia Social e Educação Ambiental da Faculdade de Ciências da Educação da Universidade de Santiago de Compostela - Galícia (Espanha) e da Ong Povoação: Educação Cidadã (Brasil). E-mail: alexvirginio@uol.com.br 
entre realidade social e contextos de cidadania e entre necessidade da política e mudança social.

Palavras-chave: Sociedade democrática. Educação. Cidadania. Formação política do educador.

\title{
Education and democratic society: sociological interpretations and challenges to political education of educators
}

\begin{abstract}
In this work we aim at pointing out the role of education in the constitution of a democratic society. The relationship between democracy and education is established by the identification of the predicates of the first, mainly from the contributions of Karl Mannheim, and the properties of the latter, especially in its political dimension, supporting the convergence between curricular processes and social needs. Based on Brazilian reality, we assert that the construction of a democratic conscience and personality stems from the achievement of another sociability, which is consonant with the values of reciprocity and cooperation, as much as sensible to the qualification of the terms that define, objectively and subjectively, the quality of life. Such quality stems, moreover, from the development of critical interpretations and/or creative proposals created as a result of and by everyday experience. Considering the precarious nature of our citizenship, as much as the ongoing educational challenges, we therefore highlight the challenge of the political education for educators. If observed and developed within ethical-political relations common to the teacher knowledge and know-how, this formative dimension can offer a humanist connotation to the process of school socialization, especially by taking into account the needs and difficulties of the popular class. More than that, it may mean the necessary mediation, although still insufficient, between the democratic project and democratic society, or even between social reality and contexts of citizenship, as well as between political needs and social change.
\end{abstract}

Keywords: Democratic society. Education. Citizenship. Political education of educators. 


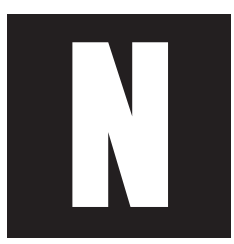

emos assistido, quase que diuturnamente e em vários espaços sociais, a discursos exortando o valor da educação para nosso desenvolvimento. São tempos em que se tornam familiares expressões como 'temos que atender às demandas de nosso crescimento com uma mão de obra mais qualificada', ou ainda, 'para garantir a inclusão de milhões de brasileiros, temos que oferecer uma educação de qualidade'. Qualidade esta, é bom que se diga, associada, em boa medida, à sua contribuição à eficácia econômica e atribuída ao domínio de determinados saberes vinculados ao saber científico-matemático e linguístico, campos do saber por onde determinados grupos sociais, diferentemente das camadas populares, transitam sem maiores percalços (Gadotti, 2009).

Esta cultura é consoante ao valor da liberdade cultuado, senão perseguido, nas sociedades democráticas. Ele está na raiz da motivação para que cada qual seja o controlador de seu destino, senhor de si mesmo na busca dos recursos necessários para atender às suas necessidades, interesses e desejos. Nestes termos, os indivíduos são responsáveis, no que concerne a sua performance no sistema de ensino, por seus sucessos e fracassos. Com efeito, o sucesso é resultado da adequação de suas escoIhas, do esforço e/ou do apoio dos outros. Em resultado, temos um sistema educativo baseado na igualdade de oportunidades, acessíveis a todos, e cujo mérito é recompensado por posições de poder, de prestígio ou de remuneração legitimados pela atribuição do diploma.

Em razão disso, ainda que escolas e professores eficazes contribuam para a redução das desigualdades de oportunidades, não se pode esquecer que há diferenças no conjunto das condições e situações prévias dos alunos. Em realidade, a cultura do esforço não atende ao princípio de justiça, visto que negligencia os efeitos das desigualdades sociais que, patentemente, impõem obstáculos (tamanho e recursos econômicos da família, 
qualidade da moradia e condições de trabalho em casa, escolaridade dos pais, recursos culturais consumidos e/ou disponíveis) aos alunos oriundos das camadas menos favorecidas.

Em conexão, uma escola justa seria, por um lado, aquela que trabaIhasse a favor da equidade, isto é, promovesse a discriminação positiva procurando beneficiar com mais e melhores recursos, com ajuda específica, aqueles que têm menos e/ou apresentam maiores dificuldades, potencializando, por suposto, suas capacidades em exercer a liberdade e, por outro lado, oportunizar e construir uma cultura de base comum, de crescimento e de desenvolvimento básico, que todos têm direito e que demanda, em meio a alunos diferentes, que apresentem domínios culturais diferentes, ou ainda, pedagogias diferenciadas permitindo que cada qual possa ser mais e melhor do que já é. Aqui teríamos uma escola que promove a socialização de todos e a singularização de cada um (Dubet, 2008).

Isto posto, gostaríamos de ponderar sobre as margens que situarão nosso argumento neste artigo. As políticas públicas e os esforços que vêm sendo empreendidos, no sentido de garantir o sucesso escolar, podem assegurar um melhor rendimento no que tange às expectativas de êxito em relação a determinadas prescrições curriculares. Todavia, são insuficientes para dar conta da necessidade de uma educação consoante a uma sociedade democrática. Trata-se de pensar para além do critério do mérito, ou mesmo do caráter instrumental do conhecimento. De modo particular, queremos colocar em relevo seu potencial em termos de capacidade de articulação (de resto, também de formação!) com o desafio posto à minimização das desigualdades geradas em outras esferas da vida social, quais sejam, de condições de vida, de emprego, de saúde, enfim, das múltiplas carências objetivas que assolam os mais desfavorecidos socialmente.

Na medida em que a desigualdade tem raízes políticas e econômicas concretas, aqui estaria um desafio para a construção de políticas públicas 
que, uma vez articuladas, desaguassem na superação da 'pobreza' do Estado e da organização e do funcionamento da sociedade, em especial quanto à garantia dos direitos de seus cidadãos (Arroyo, 2010). Esse processo, malgrado outras possibilidades, não se fará sem a participação e, ipso facto, da formação daqueles e daquelas a quem se destinam essas políticas. Sem querer minimizar o tratamento central que deve ser dado à articulação dessas políticas, centraremos nosso esforço no sentido de identificar o significado dessa perspectiva para a formação de professores. Antes, porém, faz-se necessário refletir sobre alguns traços contextuais de nossa realidade, sobre o sentido social de uma educação para e na democracia.

\section{O desafio da emergência da sociedade democrática}

Dentre nossas preocupações, causa espanto o esquecimento do que foi nodal ao pensamento de Anísio Teixeira. Segundo ele, o direito à educação é condição para que esta sociedade seja factível através do enlace e do desenvolvimento, individual e social, do espírito científico com o espírito democrático (Teixeira, 2007; 2009). É a partir deste preâmbulo que gostaríamos de recuperar, ainda que sem exclusividade e para efeito de demarcarmos as possibilidades de uma sociedade realmente democrática, as contribuições de Karl Mannheim. Seu pensamento não passou ileso das críticas quanto a seu aspecto ideológico, mormente no que respeita à sua proposta de planejamento que, como tal, visava atender a objetivos, valores e interesses previamente estabelecidos. No entanto, o que devemos reter de sua contribuição é o sentido que ele confere ao planejamento democrático, e nele o papel da educação. Preocupado com a reconstrução democrática de seu tempo, concebia o planejamento, entre outros substantivos, como tipo de pensamento e como técnica social. Esse planejamento seguirá uma orientação democrática visando a 
uma ação planificada na ordem social a partir do conhecimento das instituições e de seu entrosamento. O planejamento democrático deveria, através da educação, interferir na configuração de uma consciência e de uma personalidade democráticas, base para a transformação da sociedade (Foracchi, 1982).

Em suas contribuições, encontramos tanto a crítica ao ensino rotineiro, sem imaginação e autoritário, quanto a atenção para com a criação de oportunidades e os efeitos sociais dessas. Em sua definição mais ampla de educação, Mannheim vai sustentar que, ao dilema imposto pelas diferenças sociais e culturais, cumpre desenvolver, para todos, uma mesma educação de caráter científico e humanístico e uma diferenciação de modo a contemplar diferentes interesses e aptidões. Ele considera que o pensamento deve estar articulado ao seu contexto, oferecer ideias que tivessem repercussão social. Por isso, a educação para ele representa a possibilidade de um maior domínio do meio, isto é, o desenvolvimento de uma preocupação com os outros ${ }^{1}$ consoante e articulada com as necessidades sociais de planejamento.

Ele valoriza a comunidade e o diálogo entre indivíduo e sociedade. Com efeito, a educação escolar deve oferecer, a cada contexto e público específico, uma pedagogia particular. Os processos democráticos e as tendências igualitárias requerem, para o sociólogo alemão, mais flexibilidade

\footnotetext{
1 Na relação com o outro - em especial o mais fraco -, temos uma relação de reciprocidade, sobretudo de reconhecimento, senão de dependência, visto que o que somos decorre de nossas relações sociais. A intensificação de nosso intercâmbio social significa a potencialização de nós mesmos. Siempre necesitamos a alguien que nos necesita (Todorov, 2008, p. 150). Em outras palavras, não pode haver plenitude fora da relação com os outros, base da felicidade. Com efeito, nossa existência é sempre em referência ao 'tu'. Nesses termos, assumir a responsabilidade pela existência do outro é uma questão ontológica, uma questão ética. Ética, mormente, pois que envolve a escolha de assumir a responsabilidade por ter responsabilidade para com este outro. Fazer aprender essa responsabilidade, uma vez que não é resultado natural das relações sociais, faz-se desafio colocado à educação (Bauman, 2009).
} 
e diversidade maior na compreensão humana, considerando, também, o inconsciente e o emocional da pessoa. Em resultado, a educação deve primar pela consecução de valores que a sociedade opta como desejáveis em determinado momento histórico. Para ele, há uma relação recíproca entre indivíduo e sociedade. Em consequência, a educação deve combinar, como condição para o máximo aproveitamento das capacidades individuais, disciplina e responsabilidade, flexibilidade e liberdade. Em conexão, as metas da educação devem atender à formação do homem que se quer ser (Mannheim, 1962).

De acordo com Mannheim, uma sociedade democrática deve oferecer condições para que cada grupo possa sentir-se integrado a ela. Por isso que, para ele, a educação assume um caráter social. Cabe a ela compreender o grau de influências educativas que emanam das situações sociais de modo que seja possível construir elementos no ambiente social que favoreçam personalidades e atitudes desejáveis. Nesta medida, as instituições, as organizações e as relações entre as pessoas afetam a formação e a conduta do indivíduo. Elas podem representar, segundo Mannheim (1972), entre outras coisas, uma socialização autoritária ou uma submissão ao sistema de propriedade, do dinheiro e do desejo de possuir bens - base material do reconhecimento social. A defesa contra esta imposição social reside em uma educação em valores democráticos, de forma que o indivíduo possa desenvolver a liberdade, a autodeterminação ativa, germe da mudança social. Nas palavras de Mannheim (1972, p. 248)

As inovações se produzem, em sua maior parte, mediante a livre integração de tipos que se afastam da norma e que permanecem como opositores insignificantes fora da estrutura social estabelecida, mas contribuem amiúde com novas idéias e soluções possíveis em situações de crise no processo da transformação social. 
Na sociedade atual, os indivíduos fazem suas escolhas em um ambiente de competição ligado à busca de lucros privados e/ou na esperança de minimizar seus riscos. A questão educacional colocada é fazer ver os resultados decorrentes da competição irrefreada ou da cooperação sublimada. Uma personalidade democrática, sustenta Mannheim (1972), baseia suas escolhas na busca do bem comum em conexão com as oportunidades de progresso individual. Uma sociedade democrática não aceitaria, por exemplo, a manifestação de um comportamento arrogante, típico da elite brasileira, que se vale de sua posição privilegiada na estrutura social, de seu capital social e da ilusão da naturalização das relações sociais, bem como dos signos sociais e culturais, para assegurar vantagens no acesso a recursos materiais e culturais.

Em sentido inverso, em uma sociedade democrática, esse modo de proceder seria alvo da coerção coletiva da opinião pública, portanto, de um outro ambiente de socialização, que trataria de constrangê-lo em favor da responsabilidade social e educativa de sua ação. Aqui está o vértice da função da educação na sociedade democrática: criar as condições para a emergência de uma consciência e personalidades democráticas, de modo a interferir na conotação dos termos que definem os processos de socialização. A perspectiva considerada aqui é a de que a socialização ocorre em um contexto intersubjetivo, portanto, como um processo sem fim, no qual o indivíduo pode negar a integração normativa, ou ainda os padrões de ação e de personalidade básicas, e assumir outro modelo de atuação, tendo por alicerce outras razões para sua ação.

No entendimento de Mannheim (1972), esta outra sociabilidade estaria ancorada em uma ideia de cidadão cuja personalidade, modo de vida e ideias manifestariam uma disposição em cooperar, em respeitar a personalidade do outro, em primar pela política em detrimento da violência ou do exercício do poder pela força, que busca a integração contínua 
de diferentes propósitos e que, ao fazê-lo, mostra-se permeável ou, quando muito, de divergir simpaticamente, de apresentar outros objetivos e alvos expressos na vida em comum. Esta seria a manifestação, segundo Mannheim, de um comportamento integrador, em constante adaptação a um mundo em crescente complexidade. O progresso democrático decorreria, então, de uma educação para a participação democrática, para a divisão de responsabilidades e para o fomento à espontaneidade e a supressão das inibições da inteligência. Aqui, temos o fundamento para as descobertas intelectuais, para as novidades criadoras, para outras possibilidades de experiência de vida.

Em resumo, a educação será uma das forças, uma das técnicas ou fatores sociais destinados a agir sobre o indivíduo buscando desenvolver nele uma personalidade, em essência, democrática que manifeste, mais que tudo, disposição para encarar os desafios sociais, tolerância para lidar com as possibilidades de conflito, firmeza de caráter para sustentar determinação e resistir a influências nocivas à boa e justa convivência social e, além de tudo, capaz de operar como agente do desenvolvimento social em favor de uma sociedade que seja, em sentido razoável, o conjunto das qualidades ausentes.

Em suma, à escola caberia, através do manejo do conhecimento e da cultura, impor embaraços e dificuldades ao individualismo e à personalidade dominadora, resultados da combinação entre democracia política e economia da competição, em favor do estímulo a uma socialização, cuja autorrealização esteja fundada na participação destinada a resolver problemas da comunidade. O sistema capitalista favorece uma socialização que leva o homem a tomar tudo como mercadoria, separando-o da natureza e dos outros. A escola seria, então, o exercício da sociedade de transição, um agente socializador e dinamizador de mudanças que envolveriam o 
homem com o debate público, não mais a partir do 'pensar o outro', mas, em razão inversa, 'pensar no outro' (Mannheim, 1972; 1982).

Nessa medida, a perspectiva de ampliação e aprofundamento de um senso comum democrático demanda tecer e/ou acrescentar novos predicados ao processo de socialização dos indivíduos. Desse modo, trata-se do desafio de potencializar a dimensão política da educação formal nos processos de socialização com o fito de inaugurar e/ou desenvolver outra socialidade, cujo conteúdo pensamos ser importante destacar. A socialidade aqui deve ser pensada como todas as formas de relação ou de interação que favoreçam a constituição do indivíduo social, isto é, do ser sujeito. Em essência, seriam aquelas trocas ou situações interpessoais, e, com o mundo, marcadas por uma profunda identidade entre a esfera privada e a esfera pública. A emergência deste sujeito sugere que reconheçamos nele a indiferenciação entre individualidade e socialidade, entre querer e dever, entre indivíduo e humanidade, entre natureza e ser humano e, cuja autonomia de ser sujeito estaria condicionada pela consciência sensível da reciprocidade de sua intervenção na realidade, seja esta social ou natural. Esta autoconsciência seria responsável, ademais, pelo cuidado simultâneo para com o oicos (privado) e com a polis (público).

A construção dessa socialidade impõe, ao indivíduo, a superação dos obstáculos que a sociedade capitalista coloca às suas possibilidades de automediação e autodeterminação. Este objetivo exige que tarefas estratégicas, e de longa duração, capazes de desencadear mudanças múltiplas, complexas e processuais, venham a desembocar na intersecção entre interesses individuais e interesses coletivos. Nesta perspectiva, a ampliação dos espaços públicos de poder surge como premissa estratégica na tentativa de reaproximar indivíduo e sociedade (Max-Neef, 2006; Meszáros, 2006; Touraine, 2006). 
Esta redefinição da relação com o mundo social confere propriedade ao conceito de sujeito sustentado por Touraine (1998; 2004), qual seja, aquelas manifestações do indivíduo que luta para afirmar sua liberdade diante das relações sociais, das relações de dominação em determinado ambiente cultural e técnico. A noção de sujeito engendra todos os esforços no sentido de confecção de autenticidade, individual e coletiva, a partir do desafio da construção de um espaço social, político e moral, de produção da experiência pessoal e social. O sujeito é a antítese das normas sociais, portanto, um esforço para se dessocializar sem se perder. Nesse sentido, ele é recusa aos constrangimentos impostos pela violência, pelo mercado, pelo comunitarismo, pela cultura de massas, pelo consumo, pelo poder absoluto. Nesses termos, concede um apreço intenso à liberdade. Não há sociedade democrática sem a garantia do exercício da liberdade. O problema da liberdade é, então, tanto uma questão subjetiva quanto da qualidade do meio, do contexto que acolhe ou limita o teor de sua manifestação. Portanto, não pode haver educação que, uma vez tratando das contribuições individuais do pensamento, descuide do esforço de organização e reorganização do contexto no qual ele deve se desenvolver (Teixeira, 2000). A educação é, assim, a formação de sujeitos conscientes tanto de sua liberdade, quanto de sua responsabilidade (Touraine, 1998). Com efeito, a garantia de sua emergência se funda no reconhecimento do outro como sujeito, que tem o direito de se constituir como sujeito. Reconhecimento esse, aliás, que demanda a criação e/ou o trânsito por um espaço democrático que assegure esse direito a todos.

A democracia é tributária da constituição de um tipo de personalidade que favoreça a capacidade dos indivíduos de atuarem como sujeitos. Entrementes, são nos tempos e espaços da vida cotidiana que esse sujeito vai atuar. Nesse sentido, a participação na cena social e política requer reconduzir a participação nos espaços públicos, a luta por direitos 
e a valorização da identidade cultural às preocupações de vida e na vida dos indivíduos. A combinação entre exercício da liberdade e os processos institucionais de integração social é produto do arranjo humano. Como tal, encontra-se disposto em uma trama tecida por relações de poder. Essa é, por conseguinte, uma questão política.

Aqui encontramos, portanto, a miríade do desafio de construir uma sociedade e uma educação democrática. Uma sociedade cuja educação concorra para reduzir as desigualdades sociais, econômicas e de participação política, bem como para reforçar os critérios e as disposições de escolha diante da oferta massiva, quando não homogeneizadora, de imagens, de símbolos, de gostos e de estilos de vida. A questão que se coloca, então, é saber se os atuais processos e/ou políticas de formação docente concorrem para termos um corpo docente, em especial na educação básica, com predicados mínimos necessários para, diante da realidade brasileira, conferir um cariz democrático aos processos de socialização escolar e comunitária.

\section{Uma cidadania e uma educação ainda precárias}

Ao tomarmos por base o que expusemos até aqui, podemos sustentar que a sociedade brasileira não é democrática. Para sê-lo, não basta assegurar mecanismos formais de participação política, que deixam os mais despossuídos reféns dos interesses de grupos organizados que definem os termos da participação nas esferas de poder e/ou do Estado, que, a rigor², constitui-se em lócus no qual tramam a manutenção e ampliação de seus

\footnotetext{
2 Mesmo que reconheçamos seu papel central na garantia dos direitos humanos e na regulação social através dos, ainda tímidos e insuficientes, mecanismos de distribuição de renda e de diminuição das desigualdades.
} 
privilégios $^{3}$. Para sê-lo, irá requerer um conjunto de esforços que venham a interferir no modo habitual de pensar das pessoas, tanto quanto em suas condições objetivas de vida. Perguntaríamos: onde está o conteúdo da educação responsável por garantir a superação da consciência ingênua, aquela que favoreça a construção mental da ideia de direitos e própria para estimular a capacidade de indignação do homem simples diante dos termos, teóricos e práticos, que caracterizam sua condição de pobreza?

Sua emergência é tão mais urgente se considerarmos os termos que substantiva, na vida real, o conceito de pobreza. Entendemos a pobreza em uma perspectiva relativa e que atende, ao mesmo tempo, a uma dimensão objetiva e outra subjetiva. Em termos concretos, é relativa porque tem sua especificidade demarcada pela maior ou menor capacidade de cada qual acumular bens e satisfazer suas necessidades em sua relação com os níveis de vida considerados dignos em uma sociedade. Sua estatura subjetiva é definida pelo capital cultural utilizado pelos indivíduos, seja para perceber-se em sua realidade, seja por sua incapacidade em dispor de oportunidades para desenvolver suas potencialidades. Nesse sentido, a educação seria um dos elementos deste capital cultural (Caride Gomez, Freitas e Callejas, 2007). Ela passa a ser concebida como o vínculo passivo diante da necessidade de autorrealização. Pobreza seria então a não percepção da busca de autorrealização como necessidade (Fromm, 1979). Por outras palavras, a pobreza é material e é política. Por um lado, é ausência de renda, emprego, moradia, habitação, alimentação e saúde. Por outro, é tudo que obstaculiza a compreensão do porquê da pobreza, isto é, resultado da injusta distribuição da riqueza (Demo, 2003).

3 Privilégios estes sustentados por uma 'harmonia social' construída a partir da privatização e da desvalorização do espaço público, do sequestro da fala dos dissidentes, da anulação da política e da exclusão do discurso reivindicativo da parcela dos que têm pouco ou nenhuma parcela (Oliveira, 1999). 
Essas interpretações encontram equivalência na atual mudança técnico-científica de natureza digital-molecular, propulsora de aceleração à velocidade na e da competição e que suprime, quase que instantaneamente, a atualidade do conhecimento (Frigotto, 2007). Nesse cenário, o desenvolvimento humano sustentável é incompatível com os mimetismos, a rotina, o conformismo e o instrucionismo presentes, hegemonicamente, em nossas escolas. Colonizada pela economia, a educação busca sua justificativa na contribuição que oferece ao desenvolvimento daquela. A busca de um lugar nos espaços produtivos hipertrofia a consciência dos professores, dos alunos e de suas famílias. Em resultado e para além da geração de emprego e renda, direitos sociais relacionados à saúde, à moradia, ao transporte, à cultura, ao lazer, são pressionados para serem retirados da pauta social e/ou educacional e transferidos para o cotidiano individual da vida privada.

O quadro é mais desalentador se considerarmos que essa situação é apenas a expressão de um sistema que não garante uma educação de qualidade desde seus primeiros passos. Com efeito, é preocupante o fato de que $14,6 \%$ dos adolescentes de 15 a 17 anos estão fora da escola. Se considerarmos somente os jovens brasileiros de 18 a 24 anos, vamos constatar que 69,9\% não estudam (IBGE, 2010). Dos que estudam, 4,40\% ainda tentam concluir o ensino fundamental, 13,05\% frequentam o ensino médio, e 13,21\% é a cifra correspondente aos jovens que cursam o ensino superior. Registre-se que os jovens nesta faixa etária que estão na universidade são da ordem de 32,0\% na Argentina, 18,2\% na Bolívia, 35,9\% no Chile, 21,0\% no México e 25,1\% na Venezuela (SEDLAC, 2011) ${ }^{4}$. Esses

4 Registre-se que esses dados são referentes ao ano de 2006, com exceção da Bolívia, cujo dado é de 2005. 
dados são a expressão tão-somente de um sistema de ensino que apresenta níveis insuficientes de acesso, permanência e de desempenho, sobretudo se consideramos as diferenças de renda dos jovens que seguem estudando.

Os brasileiros têm ficado, em média, somente $7,5^{5}$ anos na escola, concorrendo para que mais da metade de sua população não tenha, ainda, sequer concluído o ensino fundamental. Apesar de termos praticamente universalizado o acesso ao ensino fundamental, permanecem problemas de acesso ao conhecimento. Convivemos ainda, por exemplo, com 1,8\% de jovens de 10 a 14 anos que não sabem ler ou escrever (IBGE, 2010). Indo nessa mesma direção, cerca de $10 \%$ da população de mais de 15 anos ainda são vítimas do analfabetismo, totalizando mais de 14 milhões de brasileiros. Nossa desonra é tão maior se atentarmos para o fato de que o analfabetismo é bem mais acentuado na população negra, nas regiões menos desenvolvidas, nos municípios de pequeno porte e na zona rural, como também de que está fortemente concentrado na população de baixa renda e nas faixas etárias mais elevadas.

Em sentido correlato, tão ou mais grave é o fato de que apenas $50,9 \%$ dos adolescentes, que estão entre os 15 e 17 anos, estudam no nível de ensino adequado. Registre-se, amiúde, que na população localizada entre os $20 \%$ mais ricos esse percentual chega aos $72,5 \%$, enquanto que na população dos $20 \%$ mais pobres apenas $31,3 \%$ encontram-se

\footnotetext{
5 Quanto mais não seja, este número esconde desigualdades regionais, diferentes resultados entre o meio urbano e o meio rural, tanto quanto nos quesitos renda e cor/raça. Assim, na região sudeste a população fica em média 8,2 anos no sistema de ensino enquanto que no outro extremo, na região nordeste, são 6,3 anos o tempo médio de escolaridade. De outra parte, aqueles que moram nos centros urbanos estudam, em média, 8,7 anos, sendo que no campo este indicador é de 4,8 anos. Acentuando as marcas da desigualdade, a realidade revela que os $20 \%$ da parcela com maior renda estudam, em média, 10,7 anos, enquanto que os pertencentes aos 20\% mais pobres apresentam escolaridade média de 5,2 anos. Quanto à cor/ raça, os números não são diferentes. Os negros ficam em média 1,7 ano a menos na escola do que os brancos (PNAD, 2009)
} 
nessa condição. Além disso, não menos sério é o fato de que as expectativas de conclusão do ensino fundamental e médio da população que frequenta esses níveis de ensino são, respectivamente, 53,8\% e 66,6\% (PNAD, 2009). Em acréscimo, estudos recentes (Torres, Bichir, Gomes, Carpim, 2008) revelam que a pior situação de acesso à escola é daquelas famílias que residem em áreas periféricas e os responsáveis pelo domicílio participam de atividades religiosas. É digno de nota que o mesmo estudo destaca o precário estímulo oferecido aos professores para atuarem nessas áreas, além do que os mesmos sustentam percepções negativas dos alunos e de suas famílias.

O público da educação pública, como os indicadores vêm demonstrando ${ }^{6}$, é marcado por uma trajetória de vida que congrega uma multiplicidade complexa de fenômenos socioculturais, bem como de subjetividades e expressividades distintas, que conferem um aspecto de singularidade às suas experiências. As dessemelhanças deste público, senão a complexidade que envolve sua caracterização, passam, ademais, por dimensões contextuais específicas. Suas vidas apresentam formas de ser, estar, pensar, sentir e proceder condicionadas por relações, interações e representações de gênero, de ocupação profissional, de lazer, de consumo e produção cultural, de etnia, de religiosidade, de formas de associação, de trânsito migratório, de composições familiares diversas, de referências espaciais, ora urbana, ora rural, de confinamento, de hábitos de higiene, de sistemas de valores, de carências e insatisfações decorrentes

6 No Brasil, do total dos estudantes, 77,5\% frequentam escolas e/ou instituições públicas. No que concerne ao acesso ao ensino médio, por exemplo, os indicadores revelam a desigualdade que existe entre a população mais pobre e aqueles que ocupam o topo da pirâmide social. Dos alunos de 15 a 17 anos que frequentam esta modalidade de ensino, os $20 \%$ mais pobres da população ocupam somente $32 \%$ das vagas, em contraste com os $77,9 \%$ correspondente aos $20 \%$ mais ricos da população (IBGE, 2010). 
das situações de vulnerabilidade social ou decorrente de direitos especiais a que têm direito, enfim, de uma variedade insondável de subjetividades que demandam uma relação política e pedagógica distinta. Acresce dizer que, para essas pessoas, que estão a cada dia lutando para conferir e/ ou renovar o sentido de suas vidas, não podemos aceitar que os processos educacionais sejam reveladores de dinâmicas curriculares assépticas, abstratas, resultado da imposição de conteúdos e temas apresentados de forma fragmentada e hierarquizada, matriz da ausência de sentido de muitas experiências vivenciadas, dia a dia, no interior de nossas escolas.

Nesta perspectiva, o desafio que está colocado é como oferecer condições e/ou situações de modo que as escolhas e/ou estratégias dos menos favorecidos não representem, como marcas de uma subcidadania ${ }^{7}$, uma inserção subalterna no sistema de ensino. Não obstante, ainda que o conteúdo escolar não esteja livre de relações de poder, devemos considerar que os alunos, ao protagonizarem o diálogo entre códigos semânticos distintos, podem construir novas categorias, novos significados que, além de ilustrarem relações sociais distintas, competem resultar em relações com a realidade distante das expectativas socialmente padronizadas (Giroux, 1997). A questão imposta requer a projeção de elementos contextuais que possam favorecer que tanto escolhas quanto estratégias desses grupos possam representar o acesso a um outro nível de racionalidade (técnica e política), capaz de conferir uma outra conotação à sua compreensão na e da sociedade, possível de lhes garantir maior autonomia, liberdade e cidadania.

\footnotetext{
7 No contexto latino-americano, e principalmente no que respeita às populações indígenas, essa categoria encontra paralelo na expressão "cidadãos de segunda". A transição do século XX para o XXI trouxe para a América Latina um processo de constituição e consolidação de sistemas democráticos que, apesar de garantirem formalmente a igualdade jurídica entre os membros da nação, sustentam regras de funcionamento da economia e da sociedade que estabelecem acessos diferenciados à cidadania. O que se tem, em realidade, é um "déficit democrático" em um sistema que se legitima pelo voto, mas que não encontra correspondência em ações estatais, sociais ou culturais que reduzam a pobreza, ampliem o acesso aos bens materiais e aos direitos de cidadania e confira um outro valor à cultura indígena (Guillén, 2006).
} 


\section{Educação, política e sociedade democrática}

Os atuais processos de sociabilidade têm desembocado, salvo as singularidades, em um modo de vida e em um mundo da vida cuja unicidade deve ser tomada a partir da forma, do simulacro, da estética, sobretudo corporal, porquanto banal, efêmero e superficial. Em suma, estamos mergulhados em um inconsciente coletivo marcado pelo senso comum intuitivo, no qual a socialidade se dá pelo desejo de imitar o outro, de ser como o outro. Ou seja, seríamos algo como 'pensados' e não 'pensantes'. Em decorrência, a identidade entre o 'eu-sozinho' e o 'eu-coletivo' ocorre em um continente de conformismo e inconsequência (Maffesoli, 2005; 2007). Correlatamente, na medida em que o mercado coloniza a cultura e os modos de vida, presenciamos a multiplicação de informações, marcas, imagens, produtos ou pluralidade de oportunidades de deslocamento e de diálogo. Em paralelo, os freios ao individualismo foram dissipados por valores hedonistas, nos quais nem a família, a religião, os partidos políticos ou o moralismo conseguem impor limites. O resultado é um homem 'desenquadrado', liberto, e que, além do descrédito com a política institucional, pauta suas escolhas políticas, sempre hesitantes e incertas, em ideias fragmentadas e por pessoas dentro dos partidos (Lipovetsky e Serroy, 2011)

Por consequência, os encadeamentos sociais, econômicos e ambientais dos processos que delimitam a sociedade em curso estão, entrementes, relativamente vulneráveis a decisões e/ou ações que explicitam suas contradições, tanto quanto representam outras alternativas de configuração social. Com efeito, a recuperação do espaço público como espaço de atuação política do sujeito-cidadão, em contraposição sujeitoconsumidor/hedonista, pretende representar o que pode ser um antídoto a este contexto. Se a privatização do espaço público tem avançado sobre todas as esferas do Estado e da Vida, as instituições educacionais democráticas têm um desafio enorme no sentido de fortalecer a cultura dos cidadãos. Seu desígnio passa a aprofundar, em cada qual, sua capacida- 
de de interpretação da realidade, senão de fazer a crítica da mesma, de modo a fazer ver a que interesses as decisões políticas institucionais estão a atender, e de modo a tornar mais visível, o poder inerente à soberania popular. Essa perspectiva está ancorada na premissa de que o acesso e a construção do conhecimento estão intimamente relacionados com os efeitos de poder. Os saberes e as relações construídas a partir do trânsito pelo sistema de ensino interferem, o mais das vezes, como filtro teórico de análise da realidade. Em outras palavras, condicionam o enfoque interpretativo da sociedade.

Aqui reside a importância da educação como ferramenta capaz de fornecer a razão de ser dos fatos, de denúncia das estruturas injustas e da recusa crítica em aceitá-las. Mais do que isso, a função política da educação está em desnaturalizar a 'feiúra' do mundo e em anunciar que os sujeitos, enquanto seres que avaliam, que comparam, que escolhem, que decidem e que agem, podem intervir no mundo, mudando-o (Freire, 2000). As referências que levamos em conta quando de nossas escolhas sobre os mais variados temas, da saúde do nosso corpo à preservação do planeta, decorrem do conhecimento que orienta nossa leitura de mundo, bem como nossa ação diante do mesmo. Trata-se de ser sujeito e não sujeitado; de pensar e não de ser pensado. É a indistinção entre concepção e execução. Nessa relação, o saber assume-se como efeito de poder (Demo, 2002).

Isto posto, não é difícil supor a substância política presente na educação. Ao colocarmos em relevo o perfil sociodemográfico das populações menos favorecidas, esses sujeitos reclamam, ainda que inconscientemente, por uma educação que, mais do que conhecimento, Ihes oportunize potencializar as formas de compreender e proceder diante das carências e dificuldades interpostas em suas vidas. Em uma sociedade marcada por desigualdades e injustiças, mais do que nunca o acesso a uma educação diferenciada adquire a conotação de um ato político a favor da emancipação social. Nas palavras de Savater (2004, p. 134), o 'fazer política' potencializa 
[...] as capacidades de opção pessoal, equilibrando por meio da educação e da redistribuição de vantagens sociais as oportunidades para que cada um possa desenvolver um projeto de vida (relativamente) próprio.

O direito ao 'poder ser mais', a acessar os caminhos que concorrem para a consecução de seu processo de humanização é premissa política de uma educação consoante à cidadania e à constituição de uma sociedade efetivamente democrática. Em consequência, é político, porquanto também pedagógico, o desafio de fazer de cada indivíduo o sujeito de sua formação, fortalecendo-o por meio de processos que favoreçam sua autoria, na medida mesmo que o desafiam em sua autonomia. Aqui reside a importância da educação não só como portadora de desafios à aprendizagem, mas como instrumento que faz do aprender uma potência que qualifica o pensamento e a ação que, em diálogo com as normas, expectativas ou representações sociais, concorrem para provocar maiores ou menores alterações nos termos que balizam as interações sociais. Com efeito, estas mudanças, mais ou menos densas, mais ou menos lentas, podem representar mudanças na qualidade de vida dessas pessoas.

Em acréscimo, a dimensão política da educação requer a participação ativa do sujeito da educação, requisito que confere sentido e significado à relação entre saber e poder. Participação esta que não é outra coisa que o ato de forjar-se na prática, de viver o direito de amadurecer. A participação como ato intransferível é o que define o indivíduo como sujeito de seu próprio desenvolvimento, em diálogo aberto com o contexto social e atento, responsavelmente, aos efeitos desse diálogo. Participação esta que, em suma, faz cada um desenvolver a consciência de seu poder, de sua cidadania ou do que é negado para obtê-la, bem como o que tem que saber e fazer para negar esta negação (Freire, 1987; Demo, 1996). Ademais, o diálogo vivo entre educação e realidade pode representar uma disposição para agir, para a desacomodação, para o rompimento de 
rotinas, para a manifestação de uma personalidade democrática, expressão ativa do sujeito de direitos em uma sociedade democrática.

\section{A educação como um ato político: desafios colocados à formação docente}

$\mathrm{O}$ ato educativo traduz as expectativas de conquista de um determinado desenvolvimento humano. É nesse sentido que devemos pensar a relação entre escola e sociedade. De modo geral, educamos para melhorar o indivíduo e a sociedade. Em outras palavras, as formações sociais, modernas e ocidentais, justificaram a educação escolar a partir da relação que estabeleceram entre seu currículo e um modelo de pessoa e sociedade previsto (Durkheim, 2001). Assim, a modernidade produziu a escola como a instituição especializada na relação pedagógica e na ação socializadora. A partir da segunda metade do século passado, a escola passa a experimentar o que se convencionou chamar de 'crise da escola'8 enquanto instituição educativa. Já faz algum tempo que o sistema escolar, em meio a um contexto em que os problemas sociais aumentam, se diversificam e se complexificam, é solicitado a dar respostas que até agora tem demonstrado pouco ajustamento e/ou adequação às mudanças sociais e culturais em curso (Esteve, 1995).

Apesar da incerteza gerada por esta dificuldade de dialogar com as mudanças de seu meio, a escola continua, inadvertidamente, a reedi-

8 Dentre os fatores desta crise, podemos destacar a democratização de acesso às salas de aula e a frustração decorrente da não correspondência entre sucesso escolar, igualdade, mobilidade social e bem-estar gerada, sobretudo, pelas mudanças em curso no contexto societário - efeitos do maio de 1968, novas formas de organização do trabalho, desemprego estrutural, precarização do trabalho, desvalorização dos diplomas, centralidade das 'mídias' nos processos de socialização secundária, agravamento dos problemas sociais e/ou da indisciplina, da incivilidade ou mesmo da violência escolar (Canário, 2006). 
tar um modelo de organização e de funcionamento compatível com um mundo que não existe mais. Dito de outro modo, ainda temos realidades escolares profundamente alicerçadas no ensino propedêutico, na desvinculação entre conhecimento cotidiano e científico; pela imposição de conteúdos a partir de certa lógica disciplinar; com tempos e espaços rígidos; com critérios de sucesso definidos pela capacidade de reprodução de textos, enunciados e fórmulas estereotipadas, bem como a imposição de comportamentos standard e baseada em uma aprendizagem mecânica que pouco ou nada pode servir de referência para outros contextos e/ou situações diferentes daquelas previstas nos manuais de ensino. Lembremos que, no ambiente nacional, os arautos da 'escola nova' já denunciavam, na primeira metade do século XX, o caráter abstrato e insípido da educação escolar (Azevedo, 2010).

Se esta é a moldura em que podemos situar as incongruências da educação escolar, é de se supor que a situação de professores mereça atenção distinta daquela que tem sido objeto até o momento. Longe de qualquer indiferença em relação ao que caracteriza o mal-estar docente e seus efeitos sobre a personalidade do professor, gostaríamos de assinalar que o desafio da emergência de uma sociedade democrática, e considerando as bases precárias de nossa cidadania, requer urgência na formação de quadros docentes, tanto quanto acréscimos qualitativos a essa formação.

O que a realidade tem revelado é que estamos vivendo uma crise na oferta de professores que tende a se agravar. Segundo os dados de 2007, 68\% dos professores da educação básica têm mais de 33 anos de idade, sendo que $24 \%$ destes tinham, à época, mais de 46 anos. Além das implicações subjetivas do envelhecimento na forma de trabalho docente ${ }^{9}$,

9 Esse é o período da carreira mais cético em relação à trajetória docente e que, malgrado casos singulares, o professor está mais permeável a um certo marasmo profissional, mostrando-se reservado diante de propostas que objetivam mudanças, julgamento fundado na profissionalidade adquirida até então (Bolivar, 2002) 
estima-se que o número de formandos nos próximos anos não venha a suprir a lacuna deixada pelo número de aposentadorias. Não obstante, a escolaridade mínima exigida para a atuação como docente nos anos finais do ensino fundamental e no ensino médio é a superior. No entanto, nossa realidade revela que somente $73,4 \%$ e $87,0 \%$ dos docentes apresentam, em um e outro desses níveis de ensino, tal formação (INEP, 2009).

Além disso, não menos grave é o fato de que boa parte dos professores atua em áreas e/ou disciplinas as quais não possuem formação característica. Em disciplinas específicas, como a Matemática, Física e Química, constatamos que somente $73,1 \%, 27,7 \%$ e 40,6\%, respectivamente, apresentam formação adequada para atuarem nessa docência (INEP, 2009; Gatti; Tarduce; Nunes; Almeida, 2010). Agregue-se a isso o fato de que nossos jovens não almejam assumir a docência como uma possibilidade profissional. Diante de uma carreira que sinaliza com baixos salários, pequenas expectativas de progressão funcional, condições de trabalho ruins, aliado à desvalorização social da profissão e do possível desrespeito e desinteresse dos alunos, aqueles que almejam 'ser professor' são, em sua maioria, jovens que provêm da escola pública, oriundos das classes $\mathrm{C}$ e $\mathrm{D}$, reconhecidamente grupos sociais marcados por uma bagagem cultural restrita (Gatti, 2010).

Em paralelo, a natureza da formação docente, tanto inicial quanto continuada, não é nada animadora. Atendendo a uma tendência da oferta do ensino superior no Brasil, a iniciativa privada acolhe a maior parte dos cursos e das matrículas destinadas à formação de professores. Segundo dados do INEP (2009a), o setor público atende a 26,4\% das matrículas dos cursos de graduação presenciais, enquanto que a iniciativa privada atende a $73,6 \%$ das mesmas. No âmbito dos cursos de formação de professores da educação básica, o setor público oferece 2729 cursos (42,9\%) e o setor privado, $3629(57,1 \%)$. No que se refere às matrículas presenciais na área específica da educação, temos 337.414 estudantes no setor público e 
405.481 que fazem sua formação no ensino privado. Esses números perfazem, respectivamente, a 45,4\% e 54,6\% do total das matrículas (742.895). Aliado a um crescimento muito tímido das matrículas nos últimos anos ${ }^{10}$, tivemos uma formação inicial dos futuros professores marcada por cursos embasados em apostilas, resumos e/ou cópias de trechos ou capítulos de livros. Além disso, são cursos que seguem uma lógica disciplinar, com pouca ou nenhuma relação dos currículos acadêmicos com os currículos praticados na escola básica e com um acompanhamento duvidoso no que se refere ao estágio docente (Gatti e Barreto, 2009; Gatti, 2010).

Diante desse quadro, alguns esforços governamentais têm sido levados a efeito no sentido de ampliar o acesso ao nível superior e, em especial, minimizar a carência de professores. Dentre as soluções apresentadas pelo Ministério da Educação, destacamos a Plataforma Freire ${ }^{11}$; a expansão das Universidades e dos Centros Federais de Educação Tecnológica; a criação da Universidade Aberta do Brasil; a criação das Instituições Federais de Educação Tecnológica (IFETs); o incentivo às licenciaturas mediante bolsas de graduação e o incentivo às licenciaturas no Programa Universidade para Todos - PROUNI. No entanto, tais medidas têm sido alvo de interpretações críticas. No centro destas, está o vínculo das políticas de formação docente às demandas da esfera do mercado, bem como sua correspondência com as orientações das agências internacionais, notadamente o Banco Mundial.

10 No ano de 2001 (INEP, 2009a), eram, ao todo, 653.813 matriculados em cursos vinculados à área da educação. Se compararmos aos atuais 742.895 alunos matriculados, temos um crescimento de somente 13,6\% em um período de quase 10 anos. Registre-se que, nesse mesmo período, a taxa de crescimento dos alunos matriculados em cursos presenciais de graduação foi de $40,8 \%$. Isso revela que, mesmo com a expansão do acesso ao ensino superior, a área da educação não se mostrou atrativa.

11 Esta plataforma congrega um conjunto de programas de formação, inicial e continuada, que compõem a atual Política Nacional de Formação do Magistério da Educação Básica. Tal política está regulamentada pelo Decreto 6755/2009. 
Em uma determinada perspectiva (Mazzeu, 2011; Coraggio, 2003; Soares, 2003; Torres, 2003; Torres, 2008), tanto os pressupostos orçamentários quanto as propostas de organização curricular das escolas e de formação de professores visam atender a um processo de adaptação às demandas do modelo de acumulação flexível do capital. Por decorrência, os organismos multilaterais ${ }^{12}$ sustentam a necessidade de uma reforma educacional para a América Latina que possibilite uma sociabilidade capaz de garantir recursos humanos 'empregáveis' na nova e maleável estrutura do mercado de trabalho. Registre-se que tal perspectiva, equivalente ao enfraquecimento do Estado nesse campo, se coaduna com as propostas de privatização e de flexibilização do mercado de trabalho e com um reducionismo economicista que submete a educação aos valores e às expectativas do cálculo econômico e/ou do mercado capitalista.

De acordo com Freitas (2011), a política de formação de professores tem recebido críticas quanto à natureza imprecisa quanto à sua qualidade. Para essa autora, a política de formação dos estudantes de licenciatura é oferecida através de programas de inserção em instituições privadas em detrimento da oferta de formação em universidades públicas. Em realidade, a escassez de professores para a educação básica tem fomentado políticas de aligeiramento e flexibilização da docência, como é o caso, por exemplo, da Bolsa Docência/CAPES, bolsa concedida a estudantes de pós-graduação para atuarem na rede pública de ensino. Além disso, várias universidades apontam para a redução na formação dos fundamentos epistemológicos e científicos, bem como dos estudos do campo da educação. O que ganha espaço é uma formação de base conteudista, ancorada na epistemologia da prática e na lógica das competências, com foco na sala de aula, longe

12 Além do Banco Mundial, a Organização das Nações Unidas para a Educação, a Ciência e a Cultura (UNESCO), o Fundo das Nações Unidas para a Infância (UNICEF), a Comissão Econômica para a América Latina e Caribe (CEPAL) e o Programa das Nações Unidas para o Desenvolvimento (PNUD). 
das problematizações que envolvem as condições de produção da vida material, da organização da escola e da educação. Tais políticas, em síntese, reduzem o trabalho docente à prática individual, às suas dimensões técnicas, para que possa ser avaliado, mensurado e certificado à luz de sua correspondência com as reformas propostas (Freitas, 2011).

No âmbito da formação continuada, as prescrições da atual política ministerial - Plataforma Freire - apontam para a integração entre educação superior e educação básica, presencial ou à distância. Isso não quer dizer que, mesmo que esta formação seja parte do cotidiano do professor - reuniões pedagógicas, palestras, seminários, encontros, cursos, projetos especiais, etc. - ela não tem conseguido superar as formas tradicionais, geralmente instrucionistas, de formação docente. Ou seja, sua qualidade é tal que pouco tem contribuído nos termos dos processos educativos. O resultado é um corpo docente preocupado em construir discursos, à luz dos temas do momento, para esconder suas práticas e não revelá-las e/ou refletir sobre elas. Em verdade, dominados pela racionalidade técnica, acabam, paradoxalmente, por reproduzir modelos de docência que são, não raras vezes, a antítese das teorias que defendem. Com efeito, as premissas ético-humanitárias, políticas e culturais não são, pelo menos em termos hegemônicos, observadas como desafios teóricos e, menos ainda, metodológicos (Virginio, 2010).

Isto posto, e considerando a construção de uma sociedade democrática, sustentamos que, aos currículos de formação de professores, poder-se-ia agregar predicados que contribuíssem, em suas atuais e futuras interações formativas, para a emergência de ideias e práticas democráticas. A questão que estamos colocando é que nas políticas de formação, além de conhecimentos científicos e pedagógicos próprios, haveríamos de edificar processos capazes de desenvolver nos professores ${ }^{13}$ :

13 Optamos por colocar esses possíveis processos no modo 'itálico' de forma a colocar em relevo o que, para nós, distingue-se por sua centralidade na sustentação de nossos argumentos. 
- $\quad$ a capacidade de estabelecer relações entre problemas que atravessam a vida cotidiana - condições de vida, situações de injustiça, de higiene, de saúde, drogas, luta contra a fome, contra a desigualdade, contra a degradação ambiental, luta pelo emprego e pela moradia, contra as formas de discriminação e preconceito, contra a manipulação genética, contra a burocratização e privatização da política, contra o conteúdo ideológico da mídia, luta pelo acesso aos direitos, ao mundo da cultura, ao lazer ... - e a percepção de que os mesmos são causa e efeito de decisões humanas e que, como tais, têm consequências políticas, sociais, econômicas, culturais e ambientais;

- $\quad$ a compreensão de que a democracia é a forma mais justa de equacionar as relações de poder, de reconhecer que os problemas de nossa época são interdependentes, que a realidade é multidimensional, complexa e de que as mudanças em curso devem merecer a compreensão de que a análise e a interferência de todos os seres humanos, nos termos de nossa existência, são um direito humano;

- a crença no sentido positivo da política, reforçando seu significado para a amplificação das possibilidades e oportunidades de felicidade a partir da participação no debate sobre a definição dos temas de interesse público, dos valores que devem permear tanto as condutas nos momentos de decidir, quanto problematizar as razões que fundamentam as decisões, as ações e as práticas correspondentes, bem como o controle sobre as responsabilidades individuais, sociais e institucionais que implicam;

- $\quad$ a sensibilidade e a capacidade de se indignar com as precárias condições objetivas e subjetivas de vida das comunidades onde atua. O conteúdo educativo do diálogo democrático poderia apreender dos dilemas cotidianos que envolvem a sobrevivência, bem como os significados atribuídos aos seus determinantes e/ou interpretações, nexo de significado que o currículo escolar tanto necessita. Aqui ter-se-ia que reconhecer, como nos lembra Arroyo (2011), a centralidade que o mundo do trabalho apresenta na vida dos coletivos populares que, da criança ao adulto, elaboram 
saberes e expectativas decorrentes das situações de trabalho ou mesmo de sua ausência;

- $\quad$ a percepção do significado que as novas configurações familiares e/ou de gênero, da cultura juvenil e do condicionamento compensatório do consumo impõem sobre o isolamento e a solidão dos indivíduos e que conferem um contorno particular às atuais manifestações de individualismo;

- $\quad$ a capacidade de propor e desenvolver dinâmicas de interpretação e de convivência com as comunidades locais de modo a potenciar a corresponsabilidade pelo desenvolvimento educacional, social e cultural, baseada no interesse pela ação, expressão da possibilidade de exercício de uma cidadania formativa e cultural mais ampla (Brant, 2009; Caride Gomez; Freitas e Callejas, 2007);

- a disposição para absorver os termos, categorias, temas de interesse da comunidade escolar no sentido de, em consonância com o espírito pedagógico democrático, oportunizar que os sujeitos possam 'dizer sua palavra', dando margem, assim, tanto à sua criatividade quanto à sua autenticidade (Virginio, 2005; Freire, 1987).

Em nosso juízo, a observação da dimensão ético-política concorre, singularmente e em nosso contexto, para a consecução de uma sociedade realmente democrática. Ela visa potencializar uma formação intelectual e moral que atenda à necessidade de aprofundamento e alargamento da personalidade autônoma, autêntica e independente do sujeito, onilateral, de modo a não dissociar sua capacitação intelectual e prática de sua intervenção na atividade social (Gramsci, 2000; Manacorda, 1990; 1996). Ademais, contribui para o reconhecimento do valor disruptivo do conhecimento em relação às representações da realidade, porquanto possuir, este conhecimento, um papel de crítica, de denúncia e de inquietação à imaginação.

O cenário social e educacional coloca, aos docentes, o desafio de atender ou não à premissa de dialogar com a necessidade de mudança, seja mudança na escola, seja mudança na sociedade. Em outras palavras, a postura passiva e conformista desemboca na 'reprodução da re- 
produção'. A postura crítica, indignada, reflexiva e inovadora concorre para somar forças na disputa de poder, entre um currículo instrucionista e um currículo emancipatório. A opção por um ou por outro campo, bem como os dilemas que envolvem cada opção, vai depender de nosso olhar para a sociedade e de nossa maior ou menor correspondência com os critérios que organizam a vida social (Virginio, 2006)

\section{Educação e sociedade democrática: formação política do educador}

Para tanto, a formação dos professores incorporaria o estudo de formas de apreensão dos saberes cotidianos construídos a partir da prática social dos indivíduos e, em paralelo, potencializar no professor o conhecimento dos elementos explicativos da realidade, do nível micro ao macro, do local ao global, das simples às múltiplas determinações, do psicológico ao sociológico, da economia à política, base conceitual para a atuação política do docente. Ou ainda, como diria Max-Neef (2006), para ativar a disposição em pensar formas alternativas para a satisfação das necessidades humanas a partir de níveis crescentes de autodependência e de articulação orgânica dos sujeitos com a natureza e com a tecnologia, processo este que será tão mais real quanto mais baseado estiver no protagonismo das pessoas.

Por conta disso é que identificamos a atualidade das contribuições tanto de Karl Mannheim quanto de Anísio Teixeira. A configuração de uma sociedade democrática é tributária de uma educação que favoreça a emergência de uma consciência, personalidade e espírito democráticos, sensíveis, sobretudo, à relevância do outro na definição dos predicados do tecido social, tanto quanto de sua importância para a construção dos mesmos. Daí resulta que não se trata de qualquer educação, mas aquela 
que, em conexão com as expectativas de relações e interações democráticas, prima pelos valores e pela prática democrática. Em consequência, as experiências de construção do sujeito democrático representam, mais do que uma reação aos padrões e às normas instituídas ou uma defesa contra a mercantilização da vida, a possibilidade de conferir potência aos princípios da liberdade e autonomia, bases fundamentais no exercício do direito de interferir nos rumos da mudança social.

Essa perspectiva, quando associada à realidade brasileira, revela nosso déficit democrático. Os contornos definidores da situação de pobreza que atinge boa parcela de nossa população, como de resto as feições de nossa desigualdade social e, em especial, educacional, revelam as dificuldades que temos para garantir a massificação, sem que isso signifique padronização de uma vida digna. Desse cenário decorre a necessidade de colocar em relevo a dimensão política da educação, qual seja, de possibilitar o acesso e/ou a construção de saberes, bem como de fomentar uma prática social, que corresponda ao exercício de corresponsabilidade na definição da qualidade do espaço público em consonância com os termos da vida privada.

Isso confere centralidade à dimensão política da educação. $\mathrm{O}$ acesso ao conhecimento especializado requer, para efeito de cidadania, a potencialização de uma disposição em valer-se dele tanto para a interpretação e crítica da realidade, quanto para justificar e mobilizar ações destinadas a intervir no espaço público. Essas são as dimensões cujos espaços de interdependência atribuem significado à formação política dos professores. Essa perspectiva pode ser melhor interpretada a partir da figura a seguir: 


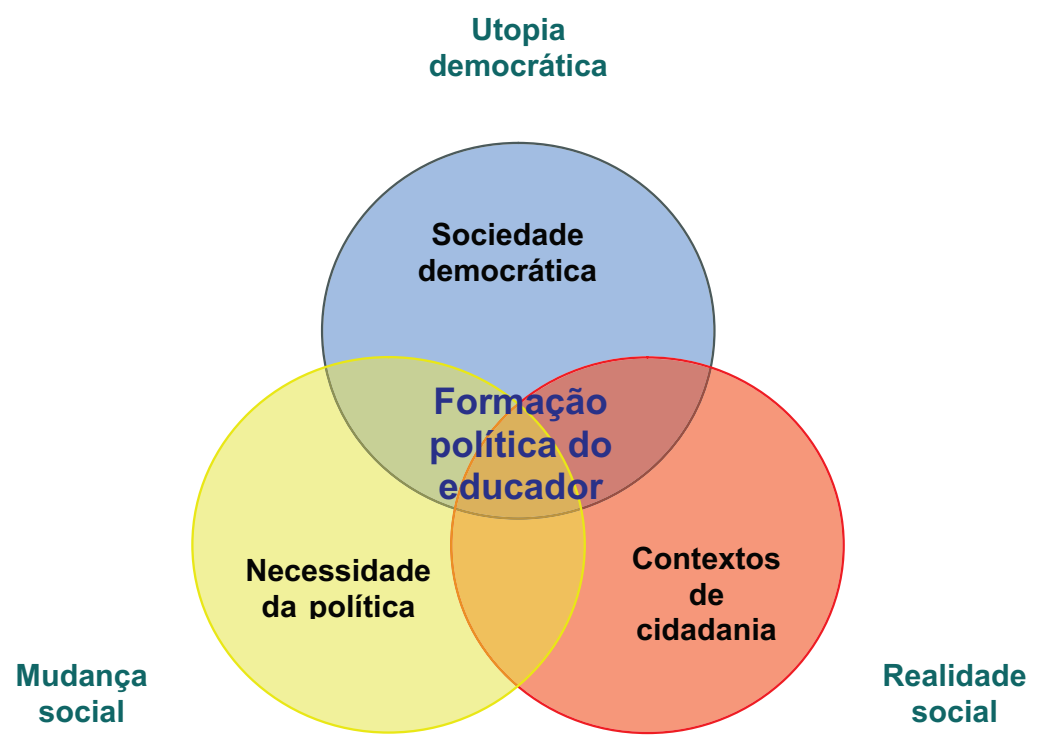

Figura 1. Esferas da formação docente

Fonte: Elaboração própria

Por certo prisma, ela é condicionada por nossas melhores expectativas. O reconhecimento das propriedades da democracia, em seu conteúdo metodológico e epistemológico, encontra pouca resistência quando consideramos sua contribuição para a qualificação do pensamento social, como também para a definição dos termos da vida cotidiana, expressão da maior ou menor conexão com a utopia democrática.

Sob outro ângulo, fazer progredir politicamente a formação docente não é algo que se faz em qualquer claustro ou mesmo abstratamente. Nesse sentido, o contato com o mundo real é premissa para estimular, 
instigar, incitar e tirar proveito formativo dos sentimentos, das dúvidas, das críticas, das inconformidades, dos apreços, dos ensinamentos que os vínculos sociais e culturais podem suscitar. Em um país em que a desigualdade social e educacional, a julgar pelos indicadores que apresentamos, segue sendo um obstáculo à garantia de direitos e à igualdade política, mudar a forma de pensar e de atuar dos professores passa por processos, políticos, de problematização de sua cultura em relação com os desafios educacionais e sociais em curso.

Por demais, é na senda entre a utopia democrática e as características de nossa constituição social que devemos observar a necessidade da política na formação dos professores. Tal formação permitiria identificar, mesmo que em probabilidade, as formas de dominação e controle, as causas da injustiça, as razões da precarização da vida ou mesmo da felicidade improvável. Em paralelo, é saber que concorre para reconhecer modos de socialidade e de ação social que, desobstruindo a liberdade de suas amarras ${ }^{14}$, faz admitir sua virtude na relação com o outro, na intersecção dos assuntos pessoais com os interesses públicos, na identidade entre interpretação individual e consciência social.

Se fôssemos tentar simplificar em poucas palavras o significado da preparação política dos educadores, teríamos que recorrer ao humanismo. O humanismo é esta expressão que não nos deixa esquecer que a mudança é inerente à história humana. Mais do que isso, é ele que permite reconhecer que a luta pela liberdade, pela justiça e pela igualdade é o que mobiliza as pessoas. Ele é a compreensão de que a história humana é um processo contínuo de autocompreensão e de autorrrealização. Ele é o que permite o diálogo entre nossa base cultural e a insurgência do sujeito (Said, 2007). Esse é o objetivo do humanismo, ou seria o objetivo da for-

14 Impostas, sobretudo, pelos conformação atual do consumismo (Ziliotto, 2003). 
mação política que, em relação com outros saberes, faz da educação um exercício de diversidade. Sua força reside, por isso mesmo, em multiplicar as formas de acesso e compreensão do mundo. Não vemos como possível que esse movimento, de fortalecimento da cultura e de ressocialização do cidadão, possa fazer-se e refazer-se sem o reconhecimento da necessidade da formação (política) de nossos professores.

\section{Referências}

ARROYO, Miguel. Políticas educacionais e desigualdades: à procura de novos significados. Educação e Sociedade, Campinas, v. 31, n. 113, p. 1381-1416, outdez. 2010. Disponível em: http://www.cedes.unicamp.br. Acesso em: 10 mar. 2011.

ARROYO, Miguel. Currículo, território em disputa. Petrópolis: Vozes, 2011.

AZEVEDO, Fernando de et al. Manifesto dos pioneiros da Educação Nova (1932) e dos educadores 1959. Recife: Fundação Joaquim Nabuco, Editora Massangana, 2010.

BAUMAN, Zigmunt. A arte da vida. Rio de Janeiro: Zahar, 2009.

BOLÍVAR, Antônio. Profissão professor: o itinerário profissional e a construção da escola. Bauru: EDUSC, 2002.

BRANT, Leonardo. O poder da cultura. São Paulo: Petrópolis, 2009.

CANÁRIO, Rui. A escola tem futuro? Das promessas às incertezas. Porto Alegre: Artes Médicas, 2006.

CARIDE GOMEZ, José António; FREITAS, Orlando Manuel Pereira de; CALLEJAS, Germán Vargas. Educação e desenvolvimento comunitário local: perspectivas pedagógicas e sociais da sustentabilidade. Porto: Editora Profedições, 2007.

CORAGGIO, José Luis. Propostas do Banco Mundial para a educação: sentido oculto ou problemas de concepção? In: TOMMASI, Lívia de; WARDE, Mirian Jorge; HADDAD, Sérgio (Orgs.) O Banco Mundial e as políticas educacionais. São Paulo: Cortez, 2003. p. 75 - 123.

DEMO, Pedro. Participação é conquista: noções de política social participativa. São Paulo: Cortez, 1996.

DEMO, Pedro. Politicidade: razão humana. Campinas: Papirus, 2002. 
DEMO, Pedro. Pobreza da pobreza. Petrópolis: Vozes, 2003.

DUBET, François. O que é uma escola justa? A escola das oportunidades. São Paulo: Cortez, 2008.

DURKHEIM, Emile. Educação e sociologia. São Paulo. Editora Melhoramentos, 2001.

ESTEVE, José M. Mudanças sociais e função docente. In.: NOVOA, Antonio (Org.). Profissão professor. Porto: Porto Editora, 1995. Cap. 4. p. 93-124.

FORACCHI, Marialice Mencarini. Introdução. In: FORACCHI, Marialice Mencarini (Org.). Mannheim: sociologia. São Paulo: Ática, 1982. p. 9 - 48.

FREIRE, Paulo. Pedagogia do oprimido. Rio de Janeiro: Paz e Terra, 1987.

FREIRE, Paulo. Pedagogia da indignação: cartas pedagógicas e outros escritos. São Paulo: Editora UNESP, 2000.

FREITAS, Helena Costa Lopes de. A nova política de formação de professores: a prioridade postergada. Disponível em: http://www.scielo.br/pdf/es/v28n100/ a2628100.pdf. Acesso em: 25 jan. 2011.

FRIGOTTO, Gaudêncio. A relação da educação profissional e tecnológica com a universalização da educação básica. Educação e Sociedade, Campinas, v. 28, n. 100, Out. 2007. Disponível em: http://www.scielo.br/scielo.php?pid=S010173302007000300023\&script=sci_arttext. Acesso em: 24 jun. 2011.

FROM, Erich. Conceito marxista de homem. Rio de Janeiro: Zahar, 1979.

GADOTTI, Moacir. Qualidade na educação: uma nova abordagem. 2009. Disponível em: http://redesocial.unifreire.org/municipio-que-educa/leituras/fundamentacao-teorica/gadotti-qualidade-educacao-forum-undime.pdf. Acesso em: 28 mai. 2011.

GATTI, Bernadete Angelina; BARRETO, Elba Siqueira de Sá (Coords.). Professores no Brasil: impasses e desafios. Brasília: Unesco, 2009GATTI, Bernadete Angelina; TARDUCE, Gisela Lobo B. P.; NUNES, Marina R. M.; ALMEIDA, Patrícia C. Albieri de. A atratividade da carreira docente no Brasil. In: Estudos e Pesquisas Educacionais, Fundação Victor Civita, São Paulo, n 1, maio de 2010.

GATTI, Bernadete Angelina. Formação de professores no Brasil: características e problemas. Educação e Sociedade, Campinas, v. 31, n 113, p. 1355-1379, outdez. 2010. Disponível em: http://www.cedes.unicamp.br. Acesso em: 20 abr. 2011.

GIROUX, Henry A. Os professores como intelectuais - rumo a uma pedagogia crítica da aprendizagem. Porto Alegre: Artes Médicas, 1997.

GRAMSCI, Antônio. Cadernos do Cárcere.. Rio de Janeiro: Civilização Brasileira, 2000. Vol. 2. 
GUILLÉN, Diana. Ciudadania versus diversidad y marginación? Sociologias, ano 9, n 18, p. 226-246, jun./dez. 2007.

IBGE. As desigualdades da escolarização no Brasil: relatório de observação no 4. In: Instituto Brasileiro de Geografia e Estatística. Brasília: Presidência da República, Conselho de Desenvolvimento Econômico e Social - CDES, 2010. Disponível em: http://www.ibge.gov.br/observatoriodaequidade/relatorio2.htm. Acesso em: 15 mar. 2011.

INEP. Estudo exploratório sobre o professor brasileiro. In: Instituto Nacional de Estudos e Pesquisas Educacionais. 2009. Disponível em: http://www.inep.gov.br/ download/censo/2009/Estudo_Professor_1.pdf. Acesso em: 05 jun. 2009.

INEP. Sinopse estatística da educação superior: graduação. In: Instituto Nacional de Estudos e Pesquisas Educacionais. 2009a. Disponível em: http://www.inep. gov.br/download/superior/censo/2009/sinopse_da_educacao_superior_2009.xls. Acesso em: 28 abr. 2011.

LIPOVETSKY, Gilles; SERROY, Jean. A cultura-mundo: resposta a uma sociedade desorientada. São Paulo: Companhia das Letras, 2011.

MAFFESOLI, Michel. O mistério da conjunção: ensaios sobre comunicação, corpo e socialidade. Porto Alegre: Sulina, 2005.

MAFFESOLI, Michel. O ritmo da vida: variações sobre o imaginário pós-moderno. Rio de Janeiro: Record, 2007.

MANACORDA, Mário Alighiero. O princípio educativo em Gramsci. Porto Alegre: Artes Médicas, 1990.

MANACORDA, Mário Alighiero. Marx e a pedagogia moderna. São Paulo: Cortez, 1996.

MANNHEIM, Karl. Introdução à sociologia da educação. São Paulo: Cultrix, 1962.

MANNHEIM, Karl. Liberdade, poder e planificação democrática. São Paulo: Mestre Jou, 1972.

MANNHEIM, Karl. Educação e planejamento. In: FORACCHI, Marialice Mencarini (Org.). Mannheim: Sociologia. São Paulo: Ática, 1982.

MAX-NEEF, Mandred A. et al. Desarrollo a escala humana : conceptos, aplicaciones e algunas reflexiones. Barcelona: Icaria/Nordan Comunidad, 2006.

MAZZEU, Lidiane Teixeira Brasil. A política de formação docente no Brasil: fundamentos teóricos e epistemológicos. Disponível em: http://www.anped.org.br/ reunioes/32ra/arquivos/trabalhos/GT05-5789--Int.pdf. Acesso em: 26 jan. 2011.

MÉSZÁRIOS, István. A teoria da alienação em Marx. São Paulo: Boitempo, 2006. 
OLIVEIRA, Francisco de. Privatização do público, destituição da fala e anulação da política: o totalitarismo neoliberal. In: OLIVEIRA, Francisco de; PAOLI, Célia (Orgs.). Os sentidos da democracia: políticas do dissenso e hegemonia global. Petrópolis: Vozes; Brasília: NEDIC, 1999. p. 55 - 81.

PNAD. Primeiras análises: Situação da educação brasileira - avanços e problemas. 2009. Disponível em: http://www.ipea.gov.br/portal/images/stories/PDFs/comunicado/101118_comunicadoipea66.pdf. Acesso em: 25 nov. 2010.

SAID, Edward. Humanismo e crítica democrática. São Paulo: Companhia das Letras, 2007.

SAVATER, Fernando. A importância da escolha. São Paulo: Planeta, 2004.

SEDLAC. Net enrollment rates: tertiary education. Março, 2011. Disponível em: http://sedlac.econo.unlp.edu.ar/esp/estadisticas-detalle.php?idE=20. Acesso em: agosto de 2011.

SOARES, Maria Clara Couto. Banco Mundial: políticas e reformas. In: TOMMASI, Lívia de; WARDE, Mirian Jorge; HADDAD, Sérgio (Orgs.) O Banco Mundial e as políticas educacionais. São Paulo: Cortez, 2003. p. 15 - 40.

TEIXEIRA, Anísio. Pequena introdução à filosofia da educação: a escola progressiva ou a transformação da escola. Rio de Janeiro: DP \& A, 2000.

TEIXEIRA, Anísio. Educação não é privilégio. Rio de Janeiro: Ed. UFRJ, 2007

TEIXEIRA, Anísio. Educação é um direito. Rio de Janeiro: UFRJ, 2009.

TODOROV, Tzvetan. La vida en común: ensayo de antropología general. Madrid: Santillana, 2008.

TORRES, Carlos Alberto. Despues de la tormenta neoliberal: la política educativa latinoamericana entre la crítica y la utopia. Revista Iberoamericana de Educación, n.o 48, p. 207-229, 2008. Disponível em: http://www.rieoei.org/rie48a10.pdf. Acesso em: 05 nov. 2010.

TORRES, Haroldo da Gama; BICHIR, Renata Mirandola; GOMES, Sandra; CARPIM, Thais Regina Pavez. Educação na periferia de São Paulo: como pensar as desigualdades educacionais. In: RIBEIRO, Luiz César de Queiroz; KAZTMAN, Rubem (Orgs.). A cidade contra a escola? Segregação urbana e desigualdades educacionais em grandes cidades da América Latina. Rio de Janeiro: Letra Capital, FAPERJ; Montevidéu: IPPES, 2008. p. 59 - 90.

TORRES, Rosa Maria. Melhorar a qualidade da educação básica? As estratégias do Banco Mundial. In: TOMMASI, Lívia de; WARDE, Mirian Jorge; HADDAD, Sérgio (Orgs.) O Banco Mundial e as políticas educacionais. São Paulo: Cortez, 2003. p. 125- 193. 
TOURAINE, Alain. Crítica da modernidade. Petrópolis: Vozes, 1998.

TOURAINE, Alain. A busca de si: diálogo sobre o sujeito. Rio de Janeiro: Bertrand Brasil, 2004.

TOURAINE, Alain. Um novo paradigma - Para compreender o mundo de hoje. Petrópolis: Vozes, 2006.

VIRGINIO, Alexandre Silva. Pressupostos epistemológicos para pensar o popular. Revista Katálysis, Florianópolis, vol. 8, n 1, p. 59 - 64, jan/jun 2005.

VIRGINIO, Alexandre Silva. Escola e emancipação: o currículo como espaçotempo emancipador. Porto Alegre/RS. 2006. Tese (Doutorado em Sociologia), Programa de Pós-Graduação em Sociologia, UFRGS, Porto Alegre, 2006.

VIRGINIO, Alexandre Silva. As propriedades do diálogo na formação de professores. Revista Profissão Docente, Uberaba, v.10 n. 21, 2010.

Recebido em: 09/08/2011

Aceite final: 29/09/2011 